\title{
CONF- $960401--60$
}

\section{SELECTIYE DISSOLUTION IN COPPER-TIN ALLOYS: FORMIATION OF CORROSION-RESISTANT PATINA ON ANCIENT CHINESE BRONZE MIRRORS}

\author{
MICHELLE TAUBE ${ }^{1.2}$, ALISON J. DAVENPORT ${ }^{2 . *}$, ALEXANDER H. KING ${ }^{1}$, AND W. \\ THOMAS CHASE, III $^{3}$ \\ 1 State University of New York at Stony Brook, Department of Materials Science and \\ Engineering, Stony Brook, NY 11794-2275 \\ ${ }^{2}$ Brookhaven National Laboratory, Department of Applied Science, Upton, NY 11973-5000 \\ ${ }^{3}$ Freer Gallery of Art, Department of Conservation and Scientific Research, Smithsonian \\ Institution, Washington, DC 20560 \\ - Present address: University of Manchester/UMIST, Manchester Materials Science Centre, \\ Manchester M1 7HS, United Kingdom
}

\section{ABSTRACT}

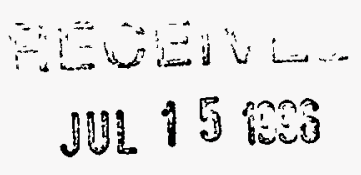

Many ancient Chinese bronze mirrors have survived with a patina that leaves the delicate relief surface decorations intact. The microstructure of these ancient mirrors is two-phase and consists of acicular $\alpha$-phase ( $\mathrm{Cu}$-rich) regions encased in a $\delta$-phase ( $\mathrm{Sn}$-rich) matrix. At the surface, there is evidence of selective dissolution of the $\alpha$ phase; the $\alpha$-phase regions are replaced pseudomorphically by a mineral product with the $\delta$ phase remaining metallic. Electrochemical polarization has been used to drive the copper dealloying process in modern, cast bronze. Synchrotron $x$-ray diffraction was employed to compare the ancient samples with those that were prepared potentiostatically. Poorly crystallized tin oxide $\left(\mathrm{SnO}_{2}\right)$ was found in the $\alpha$ replacement products of both sample types. The corrosion-resistance of the potentiostatically-treated bronze samples was tested by atmospheric exposure. Comparison with exposed, untreated samples indicated that the treatment was protective.

\section{INTRODUCTION}

Copper alloys have been considered for use in such diverse applications as nuclear waste disposal containers ${ }^{1}$ and architectural design elements ${ }^{2}$. Archaeological objects have been studied to determine how these alloys react to extended burial.' The corrosion-resistance of tinbronze is demonstrated by the abundance of bronze artifacts found in disparate environments. For example, ancient Chinese bronze mirrors have survived for 2000 years with little deterioration of their original surface decorations. Ancient bronze mirrors often have a smooth, sometimes lustrous patina. The composition of the ancient mirrors is typically $70 \% \mathrm{Cu}, 25 \%$ $\mathrm{Sn}$ and $5 \% \mathrm{~Pb}$ by weight. ${ }^{3.4}$ Bronze of this composition consists of two phases, $\alpha$ (Cu-rich) and $\delta$ (Sn-rich), arranged as $\alpha$-phase needles in a $\delta$-phase matrix. The mirrors have been labeled corrosion-resistant because the intricate details of the cast surface decorations on the backs have not been obscured by corrosion in the thousands of years since they were made. ${ }^{3.5 .6}$ However, closer inspection reveals that corrosion has indeed penetrated the surface to a thickness on the order of a tenth of a millimeter. The $\alpha$ phase near the surface has been replaced by a corrosion product with the $\delta$ phase remaining metallic. This region at the surface is known as the "altered region." The $\alpha$-phase replacement product appears to be poorly crystallized $\mathrm{SnO}_{2}{ }^{3.7}$

A selective dissolution mechanism for the replacement of the $\alpha$ phase has been suggested. ${ }^{4.7}$ Previous work by potentiostatic treatment on modern cast bronze has confirmed a selective 
dissolution mechanism. ${ }^{8}$ The microstructures of the resulting surface layers were found to be similar to those of the ancient objects.

The patinas on ancient mirrors have been tested for corrosion-resistance and found to compare favorably with modern polymeric coatings. ${ }^{9}$

The present work investigates the nature of the $\alpha$-replacement phase in both ancient and modern samples more fully through the use of $x$-ray diffraction (XRD). An atmospheric exposure experiment has been done to test the corrosion-resistance of the potentiostaticallyformed surface of modern samples.

\section{EXPERIMENTAL}

Both ancient and modern alloy samples were investigated.- Two alloy compositions were cast at Brookhaven National Laboratory. These alloys contained 10 and $25 \% \mathrm{Sn}$ by weight in copper ( $\mathrm{Cu}-10 \mathrm{Sn}$ and $\mathrm{Cu}-25 \mathrm{Sn}$, respectively). Ribbons of $\mathrm{Cu}-10 \mathrm{Sn}$, a single-phase alloy, were used as a way to isolate the $\alpha$ phase from the bulk alloy. One-inch diameter pieces of the $\mathrm{Cu}-25 \mathrm{Sn}$, two-phase alloy were used in the atmospheric exposure experiment.

The "ribbon cells" were made by embedding $\mathrm{Cu}-10 \mathrm{Sn}$ ribbons, of about $50 \mu \mathrm{m}$ thickness, in epoxy between sheets of Mylar. One end of the ribbon was left uncoated and used as the electrical connection. The potentiostatic treatment was performed by immersing the other end of the ribbon cell into solution in a beaker. In this way, the corrosion product was captured within the epoxy/Mylar matrix.

\section{$\underline{\text { Potentiostatic treatment }}$}

Two solutions were used: $0.01 \mathrm{M}$ sulfuric acid and $1 \mathrm{M}\left[\mathrm{NH}_{3}+\mathrm{NH}_{4}^{+}\right]$. The latter was a

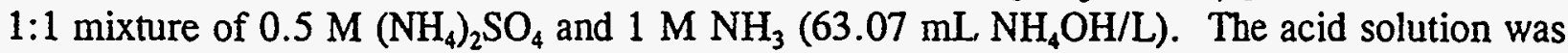
chosen because the ancient samples may have been buried in an acidic soil or treated purposely in acid by ancient craftsmen. Burial sites contain ammonia and the effect of the complexation of ammonia with copper was of interest.

Observation of the electrochemical behavior of the pure metals and alloys in the two chosen solutions allowed for selection of potentiostatic treatment potentials at which copper would be expected to dissolve and tin would be incorporated into an oxide. ${ }^{8}$

The dealloying treatments were conducted in beakers that were covered to minimize solution evaporation since the treatments extended over several days. The bronze working electrode was held at a constant DC potential versus a copper pseudo-reference electrode. The potential was periodically checked using a stable mercury/mercurous sulfate (MSE) reference electrode. High purity copper was used for both the pseudo-reference and the counter electrodes.

\section{$\underline{X-r a y ~ d i f f r a c t i o n}$}

Two types of samples were investigated: corrosion products from ribbon cells and scrapings from. ancient mirrors.

The Mylar "ribbon cells" were split open and the corrosion product was collected. Samples were scraped from the surfaces of three ancient mirrors at the Freer Gallery of Art, Smithsonian Institution with a steel scalpel. Each sample was ground with an agate mortar and pestle and contained in a fine glass capillary tube. If only a small amount of material was available, a glass rod was inserted into the capillary to keep the powder in place. The data from scrapings from the backs of mirrors JCP23 and JCP25 in the Plumer Collection are shown in this paper. 


\section{DISCLAIMER}

This report was prepared as an account of work sponsored by an agency of the United States Government. Neither the United States Government nor any agency thereof, nor any of their employees, makes any warranty, express or implied, or assumes any legal liability or responsibility for the accuracy, completeness, or usefulness of any information, apparatus, product, or process disclosed, or represents that its use would not infringe privately owned rights. Reference herein to any specific commercial product, process, or service by trade name, trademark, manufacturer, or otherwise does not necessarily constitute or imply its endorsement, recom. mendation, or favoring by the United States Government or any agency thereof. The views and opinions of authors expressed herein do not necessarily state or reflect those of the United States Government or any agency thereof. 
The data were collected at Beamline X7A at the National Synchrotron Light Source, Brookhaven National Laboratory. A position sensitive detector was used to make all of the measurements. The capillaries were spun while the spectra were being acquired. The beam width was chosen to include the powder while excluding as much of the glass as possible. The ribbon spectra were taken using an $x$-ray wavelength of $1.4020 \dot{\AA}$. The spectra of the scrapings were taken using an $x$-ray wavelength of $1.42418 \dot{A}$. The energies corresponding to these two wavelengths are below that of the tin $\mathrm{K}$-absorption edge $(29,200 \mathrm{eV})$. All results are shown in terms of $\sin \theta / \lambda$.

\section{Atmospheric exposure experiment}

Six slices, each about $2.5 \mathrm{~mm}$ thick, were- cut from a round boule of $\mathrm{Cu}-25 \mathrm{Sn}$ for an atmospheric exposure experiment. All of the pieces were polished to $0.25 \mu \mathrm{m}$ diamond finish on one face to simulate a polished ancient mirror face. Two slices were prepared potentiostatically for 48 hours in each solution. The remaining two pieces were left untreated.

The six samples were mounted on a plexiglass sheet with nylon screws. The plexiglass sheet was attached to a wooden stand at a $45^{\circ}$ angle to the vertical. The samples were alternated so that samples of different treatments were next to one another.

The sample holder was fixed on the roof of Building 480 at Brookhaven National Laboratory with the samples facing south. The samples remained there for six months starting in mid-June. Color photographs were taken at least once a week to monitor color or surface changes. A standard color chart was included in each photograph to aid in determining color shifts.

A cross-sectional metallographic specimen was made from one sample of each treatment after exposure.

\section{RESULTS}

A cross-sectional scanning electron micrograph sample of an ancient mirror is shown in Fig. 1. The bulk alloy is at the bottom left of the picture. The light grey material is the $\delta$-phase matrix. The bright white areas are lead globules; lead is insoluble in bronze. The honeycomb area above the bulk two-phase metal is the altered region. The dark material contained within the altered region is the $\alpha$-phase replacement product.

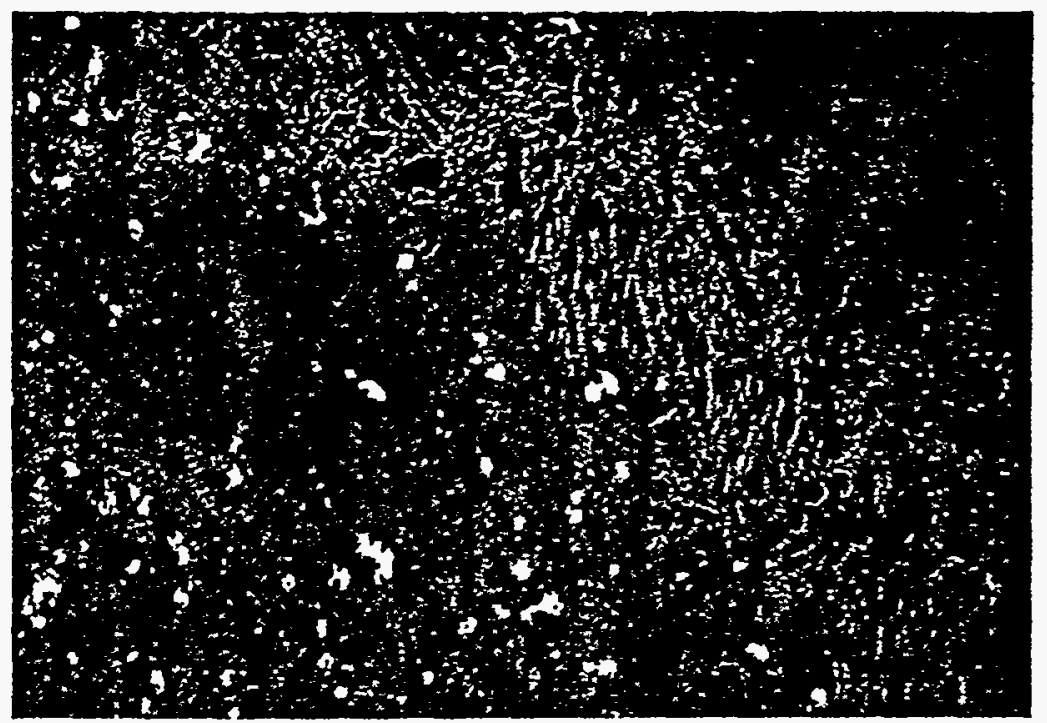

Figure 1. Cross-sectional micrograph of the surface of a Chinese mirror (FGA: JCP14) showing the c h a r a c t e r is t i c microstructure of the bulk, two-phase alloy (bottom left) below the altered region. The bright white areas are lead globules. (SEM, backscattered mode) 


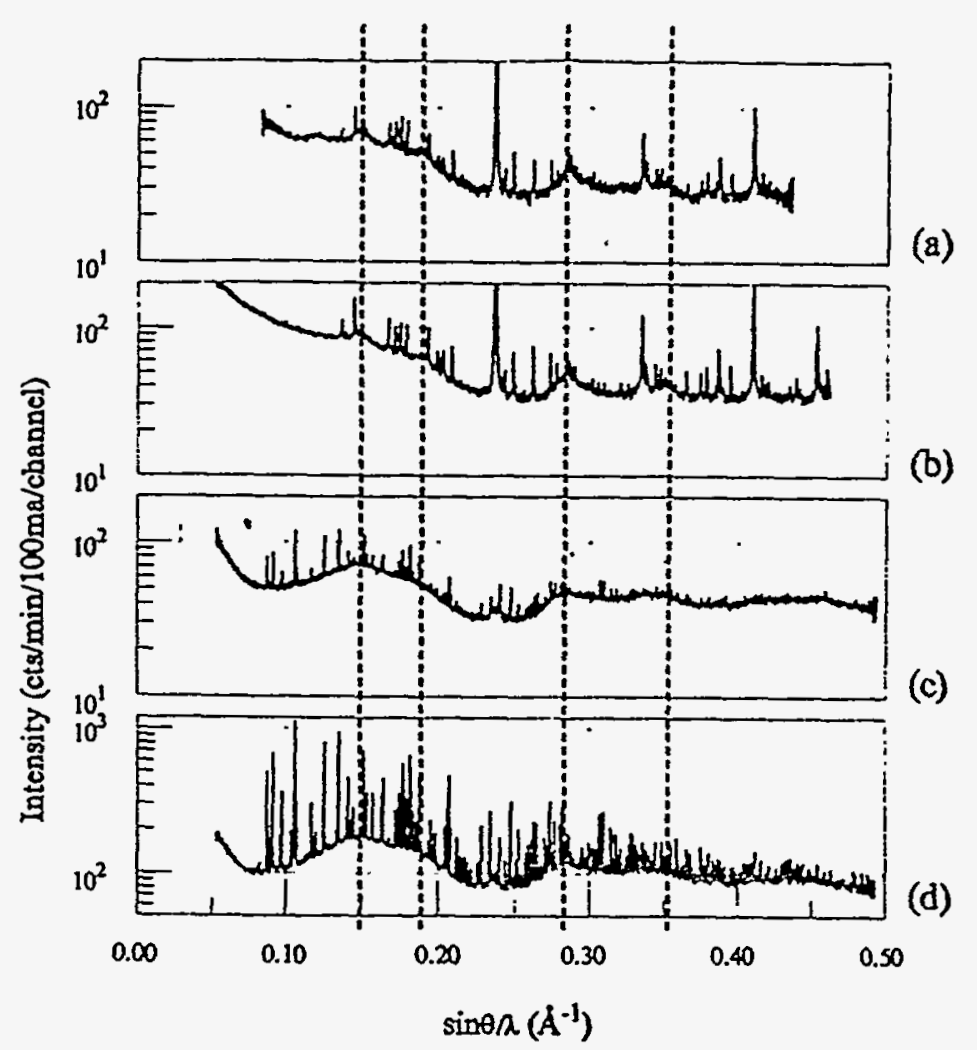

Figure 2. Synchrotron XRD patterns from ancient and modern samples: (a) ancient mirror JCP23, (b) ancient mirror JCP25, (c) $\alpha$-bronze treated in sulfuric acid, and (d) $\alpha$-bronze treated in ammonia. The vertical lines indicate the positions of the high intensity peaks of $\mathrm{SnO}_{2}$.

Figures 2(a) and (b) are XRD patterns obtained from samples taken from ancient mirror surface scrapings. Figure 2(c) is the pattern of the corrosion product formed on a single-phase $\alpha$-bronze ribbon in sulfuric acid and Fig. 2(d) is of the product formed in ammonia. The dotted lines indicate the positions of the high intensity peaks of cassiterite mineral $\left(\mathrm{SnO}_{2}, \mathrm{JCPDS} 41\right.$ 1445). We observe broad peaks at these locations in all of the specimens. The sharp peaks in the two-phase mirrors (Figs. 2(a), (b)) correspond to the metallic $\delta$-phase matrix. The $\delta$ phase is expected since the scraping removed portions of the altered region which contains $\delta$-phase metal. The sharp peaks in Figs. 2(c) and (d) correspond to the mineral chalcanthite $\left(\mathrm{CuSO}_{4} .5 \mathrm{H}_{2} \mathrm{O}\right.$, JCPDS 11-646). Sulfate was the anion in both solutions.

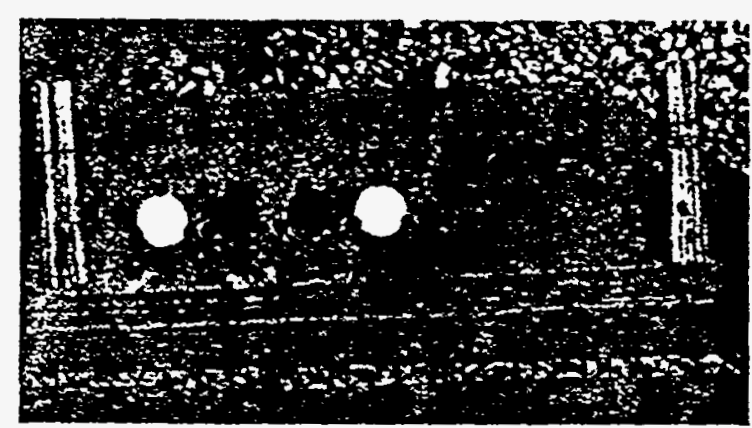

(a)

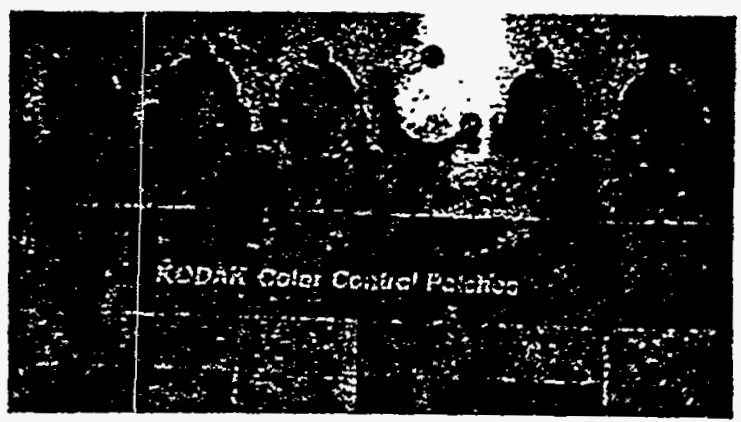

(b)

Figure 3. Atmospheric exposure samples: (a) the first day of the experiment and (b) after 6 months exposure. The samples were, from left: untreated, ammonia-treated, acid-treated, untreated, ammonia-treated, acid-treated. The untreated samples appear cloudy after exposure. 


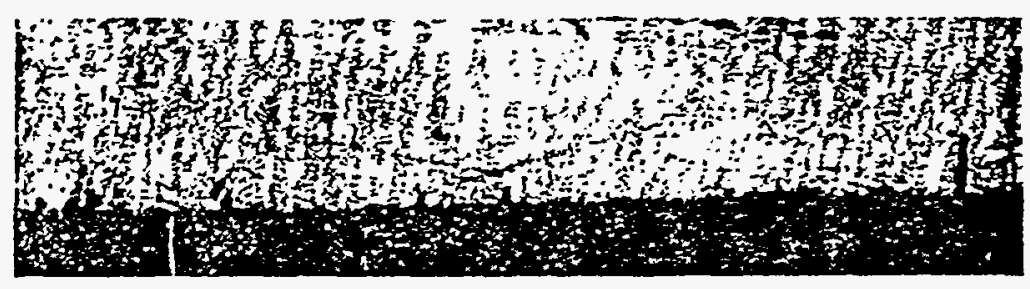

$10 \mu \mathrm{m}$
Figure 4. Optical micrograph of cross-section of untreated sample after six months atmospheric exposure. The two-phase bulk material is visible (top). At the surface, preferential attack of the $\alpha$ phase is seen in places.

Figure 3(a) shows the atmospheric exposure samples on the first day of exposure. A photograph of the samples after six months exposure is shown in Fig. 3(b). The samples were, from left: untreated, ammonia-treated, acid-treated, untreated, ammonia-treated, acid-treated. The appearances of the treated samples have not changed visibly. The untreated samples, however, appear cloudy after exposure.

An optical micrograph of a cross-section of one of the untreated samples is shown in Fig. 4. The two-phase bulk material is visible; the $\alpha$ phase appears light in a darker gray $\delta$-phase matrix. At the surface, preferential attack of the $\alpha$ phase is seen in places.

\section{DISCUSSION}

The diffraction patterns of the ancient mirror samples and those of the modern single-phase material have a similar background shape. This shape can be seen to contain broad "peaks" at the positions of the high intensity peaks for crystalline tin oxide. The better definition in the patterns of the ancient samples could be due to the age of these samples which allowed the material to become more crystalline. Gettens reports diffuse lines in the XRD patterns of samples of ancient bronzes with a similar microstructure (i.e., altered region). ${ }^{7} \mathrm{He}$ attributes these peaks to a hydrated form of $\mathrm{SnO}_{2}$. The line-broadening may also be due to very small crystal size. The $\alpha$ replacement product in treated, two-phase bronze is currently being investigated with transmission electron microscopy.

The altered region formed by potentiostatic treatment of bronze appears to be protective since only the untreated samples were visibly different after six months of exposure. The $\alpha$-phase replacement product appears to act as a diffusion barrier to prevent further corrosion after treatment. Selective dissolution of the $\delta$ phase is sometimes seen in ancient samples. The observation of preferential attack of the $\alpha$ phase in the untreated samples may be of consequence when determining the causes of attack of each phase in an uncontrolled environment such as a burial site.

\section{CONCLUSIONS}

1. The $\alpha$-phase replacement product produced by potentiostatic treatment of bronze is similar to that found in the altered layer of ancient Chinese mirrors. Both modern and ancient samples contain poorly crystallized $\mathrm{SnO}_{2}$.

2. Potentiostatic treatment of two-phase bronze produces a protective, corrosion-resistant surface. 


\section{ACKNOWLEDGMENTS}

This work was performed in part under the auspices of the U. S. Department of Energy, Division of Materials Sciences, Office of Basic Energy Sciences under Contract No. DE-AC0276CH00016. We would like to express our gratitude to Joseph Hriljac and Cahit Eylem for assistance with data acquisition and analysis at Beamline X7A, and Kenneth Sutter and Kathryn Warburton for assistance in sample preparation.

\section{REFERENCES}

1. R.F. Tylecote, J. Archaeol. Sci. 6, 345-368 (1979).

2. S. Virtanen, H. Wojtas, P. Schmuki, H. Boehni, J. Electrochem. Soc. $140(10), 2786-90$ (1993).

3. W.T. Chase and U.M. Franklin, Ars Orientalis XI, 215-258 (1979).

4. N. Meeks in Metal Plating and Patination - Cultural, Technical and Historical Developments, edited by S. La Niece and P. Craddock (Butterworth-Heinemann Ltd., Oxford, 1993), pp. 63-84.

5. R.J. Gettens, Technical Studies in the Field of Fine Arts III(1), 29-37 (1934); Bulletin of the Fogg Art Museum 11(1), 16-26 (1949).

6. W.F. Collins, J. Royal Anthrop. Inst. 64, 69-79 (1934).

7. R.J. Gettens, The Freer Chinese Bronzes, Vol. II, Technical Studies, (Smithsonian Institution, Washington, D.C., 1969), pp. 186-191.

8. M. Taube, W.T. Chase, A.J. Davenport, A.P. Jardine in Materials Issues in Art and Archaeology IV, edited by P. Vandiver, J. Druzik, J.L. Galvan, I. Freestone and G.S. Wheeler (Mater. Res. Soc. Proc. 352, Pittsburgh, PA, 1995), pp. 215-221.

9. L. Soto, J.P. Franey, T.E. Graedel, G.W. Kammlott, Corros. Sci. 23(3), 241-250 (1983). 